\title{
THE USE OF METROPOLITAN COUNCILS IN THE URBAN COMMUNITY
}

\section{JOHN W. BODINE $\dagger$}

In commenting on Senator Clark's address, I would like to emphasize the special problems of those metropolitan areas which spread across several state lines. There are, of course, metropolitan areas that are not interstate. Miami and Cleveland, for example, are each within one sovereign state, and that sovereign's reserve of power is available to each of them if needed. The San Francisco and Los Angeles areas may have their growing pains, but if either of them needs additional powers to deal with the situation, it can go to Sacramento and get them. But a very large proportion of the country's total population lives in metropolitan regions like that centering on St. Louis, whose urbanized area extends across the Mississippi into Illinois, or Chicago, whose sprawl extends in part into Indiana. And I would like to call special attention to the complex metropolitan areas that spread out from Washington, D. C., from Philadelphia, and from New York City. Each of these areas extends into more than two states and presents in acute form the lack of congruence to which the Senator refers between modern problems and inherited forms of local government. What hope is there for the extension of the legal order to meet the pressing needs of these especially complex areas?

The Washington area is different from that of Philadelphia or New York because the county governments in Maryland and Virginia have wider powers than their northern counterparts, and the number of autonomous municipalities in the region around Washington is correspondingly smaller than in the Philadelphia or New York areas. Further, the federal government not only is sovereign in the District of Columbia, but also has important powers in the territory of the two adjoining states. In the tri-state area from Trenton to Wilmington, however, there are eleven counties and no less than 377 municipalities, and in the tri-state area around New York City there are twenty-two counties and 551 municipalities.

These three areas may not be the most rapidly growing in the country, but their populations are nevertheless increasing by leaps and bounds. In a mere decade, from 1950 to 1960, the twenty-two counties

$\dagger$ President and Executive Director of Pennsylvania-New Jersey-Delaware Metropolitan Project, Inc. (Penjerdel). 
in the New York City area increased by almost 2,200,000 people, or about sixteen percent. In the same decade the four counties and three independent cities circumjacent to Washington, D. C., added 540,000 people, or thirty-seven percent. And in those ten years the eleven counties from Trenton to Wilmington increased by 806,000 people, or nineteen percent. In each case the principal core city actually declined in population, and in the Philadelphia area the ten counties surrounding the principal core city increased in those ten years by forty percent.

As the Senator has pointed out, the problems resulting from this rapid growth have a clearly interstate character. In the Philadelphia area the prevailing southwest winds blow smoke and smells from Delaware and Pennsylvania across the river to New Jersey. Untreated sewage flowing into the tributaries of the Delaware in one state pollutes the river for the other states, complicating their water supply problems and ruining for all three states the usefulness of the river for recreation. In 1955 when the Delaware went on a rampage, its overflowing waters ravaged each of its bordering states. The tri-state region around Philadelphia has for all practical purposes one mobile labor market; a person living in one part of the tri-state area can conveniently hold a job in almost any other part of the area. As a result, the problems resulting from the imbalance between the supply and demand of labor must be considered on an interstate basis. If there is a shortage of computer operators in Camden, New Jersey, there is no point in setting up an extensive training program in Camden if at the same time there is a surplus of such operators across the river in Philadelphia. But as the Senator has indicated, the most urgent interstate problems in such complex areas are those involving physical development: the problem of bringing some kind of order out of our suburban sprawl. Among the evils of our disordered growth is the indiscriminate chewing up for residential purposes of the land the region will desperately need in the future for specialized uses such as parks, industrial sites, or even sites for reservoirs. Another piecemeal policy results in large-lot zoning in the farther-out suburbs, often motivated not by considerations of land use, but by a desire to keep down school costs regardless of the great increases in other costs produced by large-lot zoning. School costs must be met by school districts on the same level with the municipality having zoning power, whereas the parallel increases in costs of utilities, streets, and especially transportation must be met by direct outlay of the residents, or by the more remote state and federal agencies. How to mobilize the forces of government to deal with issues such as these in complex metro- 
politan areas is believed by many observers to be today's most baffling challenge to our system of local government.

To meet this challenge we will have to have recourse to a wide range of disciplines, chiefly in the social sciences; but it is clear that no amount of social engineering will suffice unless the new patterns are institutionalized by law. It is not only that lawyers have the keys to the intricacies of our constitutional system, to the division of powers between our different levels of government, and to the niceties which must be observed if, for example, two or more states are to join hands to meet some pressing public need; lawyers are needed also because of their skill in sorting out and reconciling conflicting interests.

The skills of our profession have already been drawn upon in devising structures to meet some of the most urgent problems of the multi-state metropolis. Senator Clark has mentioned the Delaware River Port Authority and the Delaware River Basin Commission as examples of agencies created by interstate compact with congressional approval. He has also mentioned that some of the more vexing problems of metropolitan development have shown a tendency to gravitate upward to the state and federal governments, and he gave highway planning as an illustration. In some interstate metropolitan areas it has been found that highway planning cannot really be done by these familiar levels of government-not by the federal government, because of its remoteness from the many local issues involved in highway planning, and not by any state acting alone, because of the necessarily interstate character of highway planning in a metropolitan area crossing state lines. The result in the regions spreading out from New York City and from Philadelphia has been the creation of interstate agencies by the relatively simple means of executive agreement. In the Philadelphia area, for example, two of our three states joined to form the Penn Jersey Transportation Study, which is engaged in a massive analysis of the transportation problems of the metropolitan area centering on Trenton, Camden, and Philadelphia. Steps are now underway to broaden the study to include Wilmington, New Castle County, and the state of Delaware as well.

These and various other examples could be cited of agencies which the law, with due regard for the constitutional niceties, has created to deal with metropolitan issues crossing state lines. However, it is important to observe that, whatever may have been the experience in other interstate metropolitan areas, in the areas around Philadelphia and New York the structures so far erected each deal with only one function of government. As the Senator points out, it has not yet been found possible in these complex metropolitan areas to 
create institutions performing more comprehensive functions, such as a regional planning commission.

It is tempting to suppose that, even in the multi-state metropolitan areas, all our troubles would be over if only we could erect a multi-purpose metropolitan government. If such a government were to cover the entire urbanized area spreading out from New York City or from Philadelphia, for example, it would have in each case to cover portions of three separate states. Presumably this new government would exist by delegation of powers from each of the three states supplying parts of its territory, and presumably it would be superior in powers to the existing county and municipal governments within that territory. A ready analogy is the bringing together of the territory within Philadelphia County under one city government by the Incorporation Act of $1854,{ }^{1}$ or the reorganization about 40 years later that produced New York City. ${ }^{2}$ The Senator has given us more recent examples.

No doubt the theoretical problems of creating such a government could be solved. A legal and political tradition that has made our federalism work for so many years should be capable of defining the powers to be conferred on such a government and those left to the states, counties, and municipalities. Similarly our experience to date with the intricacies of taxation and public finance among several levels of government competing for essentially the same sources of revenue should make it possible for us in theory to separate out and define the sources which could be made available for the support of such a new level of government.

Other more difficult questions would arise from the dispersion of public attention and control if the existing municipalities were to continue to perform some local functions of government. When all of the municipalities in Philadelphia County were consolidated into the City of Philadelphia, the voters thereby put all their eggs in one basket, and it was relatively easy to watch that basket. But if the voters of the tri-state area around Philadelphia created a metropolitan government, would they abandon the local governments to which they are accustomed? If not, would they have difficulty keeping their new metropolitan government under scrutiny, in addition to the federal, state, county, and municipal governments continuing to exercise public responsibilities?

My own opinion is that, however skillfully we might solve these questions, and no doubt the skills of lawyers would be indispensable to

1 An Act To Incorporate the City of Philadelphia, Pa. Laws 1854, No. 16 (codified in scattered sections of PA. STAT. ANN. tit. 53).

2 N.Y. Sess. Laws 1894, ch. 64. 
their solution, the practical problems of creating such a government by simultaneous and uniform action of several state legislatures, and presumably with the constitutionally required congressional consent, are so formidable that we should look first for other more practical solutions.

In Atlanta and Nashville, and in Dade County surrounding Miami, as the Senator has said, such fundamental changes have been approved; but in each case only one state, and indeed only one county, was involved. The Incorporation Act of 1854 did not attempt to combine Camden with Philadelphia, nor were Jersey City and Hoboken ever consolidated with New York. The larger the area to be consolidated, the greater is the variety of interests to be reconciled and the more numerous are the ties to be broken between citizens and the governments to which they are accustomed.

In this situation are there practical alternatives? Senator Clark mentions the creation of interstate agencies, and offers as examples the Port Authority and the River Basin Commission in the Delaware Valley. I would not deny the effectiveness of these agencies. In their attempt to deal one by one with separate functions of government they are comparable to another avenue of progress, namely, voluntary cooperative arrangements between autonomous governments. Voluntary cooperation has already resulted in numerous agreements on a great many subjects. These range from simple topics like snow removal from boundary streets to the more elaborate agreements required for police networks to apprehend fugitives. They include school jointures, sewer agreements, and even joint planning activities. It is not beyond the realm of possibility that a regional planning commission, with advisory powers only, could be created by such a network of agreements. The Penn Jersey Transportation Study and the Southeast Pennsylvania Transportation Compact were so created.

But these agreements for the most part suffer from the same limitation as the interstate agencies previously mentioned-each of them customarily deals with only one function of government. What machinery can be developed, what regional institution, which would be flexible enough to deal with a wide variety of functions? I believe that the most promising step in this direction can be seen in the emergence of metropolitan councils. These are voluntary associations of officials or governments on a region-wide basis, and they have been created within the past few years in several interstate metropolitan areas. These councils ordinarily represent a wide range of governments from throughout a metropolitan area, and are organized and controlled by the officials themselves. 
In the area around Philadelphia the council of this type is called the Regional Conference of Elected Officials. Its membership is open to the chief elected official of each county and municipal government in the eleven-county region. It has advisory powers only, and cannot order anyone to do anything. But its program is sufficiently flexible so that, unlike the existing interstate agencies, it can apply itself to whatever interjurisdictional problem may arise. And while it may not have power to settle anything, it can provide a forum where agreements can be reached, or where disagreements can be bargained to agreement.

No doubt the effort to solve these interjurisdictional questions by erecting one interstate agency after another and by entering into one cooperative agreement after another is slow and uncertain. It is subject to numerous vetoes, but then it can also be extended by a bandwagon effect. An agreement which results in lower costs and greater efficiencies can look quite attractive to the nearby governments who are not yet participants. This process of adding one arrangement to another is intensely practical, dealing opportunistically with one problem after another, coping with this situation where the way opens, and deferring where understanding is lacking or opposition too strong. It presents certain analogies to the gradual integration of Europe which is now going on, with one specialized international agency being built after the model of a predecessor, until with the Common Market a voluntary network of great economic significance is being woven. It also presents analogies, as the Senator has said, to the gradual growth of the common law. And if it can be coupled with a metropolitan council, such as the Regional Conference of Elected Officials, with a program susceptible of attention to any regional issue, the important capstone of top-level generalized responsibility is placed on the existing specialized structures. Such a conference may lack power, but so does the United Nations. Such a conference may well provide the forum where a true sense of community in the region can be voluntarily worked out, and where regional opinion, as sensed by elected officials, can finally find expression.

I submit that, whatever quicker methods may be available in the less complex metropolitan areas, we will use our resources of good will and public spirit in the multi-state areas more economically if, before tackling the monumental difficulties of a general metropolitan government, we fully explore the possibility that voluntary cooperation can do the job. And in this endeavor I submit that lawyers are especially well qualified to take a leading part. 
As we all know, the law is a process for reducing to order man's relations with his fellows. Our legal system of necessity has a polemic side, involving advocacy and enforcement. But it also, and more significantly for the present discussion, has a patient role of seeking accommodations and working out agreements, of bringing the wisdom of history and the detachment of professionalism to resolve the conflicts of society. It is these talents of the lawyer and these traditions of his craft that can to my mind be of greatest use in extending political and legal order in the multi-state metropolis. 